\title{
FBI confirms no evidence to back Oppenheimer charges
}

\begin{abstract}
Washington. US President Bill Clinton's Foreign Intelligence Advisory Board (PFIAB) this week released a brief statement from the Federal Bureau of Investigation (FBI) saying that the bureau had found no "credible evidence" behind allegations that four senior physicists on the Manhattan Project spied for the Soviet Union, and that it believes the allegations to be false (see Nature 374, 581; 1995).
\end{abstract}

The allegations were made last year by former Soviet spymaster Pavel Sudoplatov in his book, Special

Tasks. Since then, they have been furiously disputed by US physicists and friends of the four men, all of whom are now dead.

This week's statement takes the form of a letter sent to Les Aspin, chair- Aspin: 'names not on man of PFIAB, list of Soviet spies'. from Louis Freeh,

director of the FBI. The letter says that the bureau "is not in possession of any credible evidence that would suggest that Niels Bohr, Enrico Fermi, Robert Oppenheimer, or Leo Szilard engaged in any espionage activity on behalf of any foreign power to include that involving atomic bomb secrets."

The letter continues: "Indeed, the FBI has classified information available that argues against the conclusions reached by the author of Special Tasks. The FBI, therefore, considers such allegations to be unfounded."

At a press briefing in Washington at which the statement was released, Aspin said that type of classified information referred to by the FBI included lists of names of people who had helped the Soviet Union with its nuclear weapons programme, and had been obtained by the US government. "These lists exist and these [four] names are not on them," Aspin said.

Aspin characterized the investigation as "a small effort" which had focused on a single question - whether evidence existed to confirm or refute Sudoplatov's allegations. The FBI, he said, had found no evidence either way in its files. But it had concluded on the basis of the "other evidence" that Sudoplatov was wrong.

The investigation was instigated by Sid Drell, deputy director of the Stanford Linear Accelerator Center in California and a member of PFIAB. But Aspin agreed that it may not be the last word on the matter.

At Monday's briefing, Jerrold Schecter, who helped Sudoplatov write the book, called on the US government to declassify records of coded messages which were passed from Soviet agents in the United States to Moscow at the time but were intercepted by US officials. Schechter said that these intercepts would resolve the question.

Colin Macilwain

\section{Anomaly admitted in 'first' AIDS case}

London. The researcher responsible for claims - recently called into question that the world's first AIDS patient was a 25-year-old apprentice printer who died in Britain in 1959 has acknowledged he knew his results may have been anomalous, even at the time of conducting his analysis.

In a co-authored letter to The Lancet, Gerald Corbitt, director of clinical virology at the Manchester Royal Infirmary, also admits that he was aware in 1992 that the apprentice, David Carr, could not have died of AIDS, as the HIV detected in tissue samples analysed in 1990 were from "a relatively modern strain".

Corbitt was responding to findings published last month by David Ho, director of the Aaron Diamond AIDS Research Center in New York, which challenge the researcher's original claims that Carr was the first recorded AIDS death (see Nature 374,$503 ; 1995$ ).

Having reanalysed Carr's tissue samples, Ho, who had been cooperating with Corbitt, concluded that the strain of HIV detected could not possibly have existed in 1959. Further samples taken from Carr's kidney and bone marrow subsequently tested HIV-negative, suggesting that the collection of tissues could have come from two separate individuals.

In a letter commenting on Ho's findings and published in The Lancet on 22 April, Corbitt says that the findings "confirm our own view", based on "sequencing work done in the two years after publication."

Asked this week why he failed to publish his doubts about his initial findings sooner, and thus clear up the confusion over the identity of the first AIDS case, Corbitt says he felt no reason to do so.

Corbitt contends that his original 1990 letter to The Lancet, was not intended as "a peer-reviewed article" on the origin of AIDS. The motivation behind analysing Carr's tissue, he adds, was simply "to see whether we could use PCR on archival material".

\section{MRC agrees terms of access to gene sequence databank}

London. Britain's Medical Research Council (MRC) has reached agreement with SmithKline Beecham (SB) and the Institute for Genomic Research (TIGR) on the terms under which MRC scientists will be allowed access to 150,000 human gene sequences generated by collaboration between by TIGR and Human Genome Sciences Inc.

Initially, MRC officials had voiced strong criticism of some of the terms being required by HGS for access by academic scientists to its databases, and had told scientists funded by the council, including 4000 scientists working in British universities and medical schools, not to accept the conditions being offered (see Nature 373, 376; 1995).

In particular, their concern had focused on proposed clauses limiting the freedom of scientists to discuss work using information from the data-base with colleagues in the same laboratory, and others giving HGS a first option on any commercially-valuable research results emerging from the use of the data.

David Owen, head of licensing for the MRC, said on Monday that the agreement that has now been negotiated with $\mathrm{SB}$, one of Britain's largest pharmaceutical companies, meets many of these early concerns. "We have tried to go for a UK solution," says Owen, arguing that the way that the obligations of researchers in early draft agreements proposed by HGS was to be met was "not as clear as it could have been."

As far as the first option clause is concerned, for example, Owen says that the new terms establish that SB/TIGR "must present us with firm evidence that they are going to exploit the discovery and not sit on it."

Craig Venter, the president and director of TIGR, said that he was "very pleased" that agreement had been reached with the MRC. Venter claimed that difficulties in the past had been partly the result of confusion between TIGR and HGS. (The two bodies are formally independent, although the Human cDNA Database, which is managed and operated by TIGR, is supported financially by SB and HGS).

Last year, HGS reached agreement with the Howard Hughes Medical Institute (HHMI) on the terms under which HHMI scientists are permitted access to the database. According to Venter, similar agreements have now been signed with more than 50 research institutions world-wide.

However negotiations are still taking place with the National Institutes of Health (NIH), which is faced with the need to reconcile the access conditions that it is being asked to accept with the political pressures that inevitably impinge on the biomedical research agency.

David Dickson 